\title{
PENINGKATAN KEMAMPUAN APRESIASI PUISI BAGI SISWA DI SANGGAR BACA JENDELA DUNIA CIPUTAT TANGERANG SELATAN
}

\author{
Bram Denafri $^{1^{*}}$, Taat Budiono ${ }^{2}$, Irwansyah ${ }^{3}$, Dewi Yanti ${ }^{4}$ \\ ${ }_{1,2,3,4}$ Sastra Indonesia, Universitas Pamulang, Indonesia \\ bram@unpam.ac.id ${ }^{1}, \underline{\text { budionotaat@gmail.com }}^{2}$, awakimed@gmail.com $^{3}, \underline{\text { dosen01160@unpam.ac.id }}^{4}$
}

\begin{abstract}
ABSTRAK
Abstrak: Kegiatan ini bertujuan untuk membantu Sanggar Baca Jendela Dunia dalam mewujudkan misinya, yaitu memberikan pelatihan di bidang bahasa dan sastra. Selain mewujudkan salah satu misi Sanggar Baca Jendela Dunia. Kegiatan ini juga bertujuan untuk memperingati Bulan Bahasa. Dengan harapan, dapat membina, mengembangkan dan mewariskan Sastra Indonesia kepada generasi muda. Selain itu, kegiatan apresiasi puisi dapat mempertajam perasaan, penalaran, daya khayal serta kepekaan generasi muda terhadap masyrakat, budaya dan lingkungan hidup. Adapun tahap realisasi permasalahannya adalah dimulai dengan pengajaran materi pembacaan puisi kepada para peserta. Hal ini dilakukan dengan harapan agar para peserta memiliki pengetahuan teori tentang pembacaan puisi. selanjutnya, dilakukan pengkajian atau analisis makna yang terkandung dalam puisi. hal ini, bertujuan agar peserta bisa menganalisis dan memahami makna yang terkandung dalam puisi sehingga dalam pembacaan puisi bisa lebih menghayati. Setelah itu dilakukan kritik teks puisi dalam upaya untuk mengetahui kelebihan dan kekurangan dari sebuah teks puisi. Selanjutnya, dilakukan praktek pembacaan puisi dengan harapan agar peserta dapat menerapkan semua teori tentang puisi dalam pembacaannya.
\end{abstract}

Kata Kunci: Apresiasi Puisi; Sanggar Baca Jendela Dunia.

Abstract: Lecturer at the Indonesian Literature Study Program at Pamulang University took the initiative to conduct Poetry Appreciation Training at the Window Window Study Studio This activity aims to help Sanggar Baca Jendela Dunia in realizing its mission, which is to provide training in the fields of language and literature. Besides realizing one of the Sanggar Baca Jendela Dunia missions. This activity also aims to commemorate the Language Month. With hope, can foster, develop and pass Indonesian Literature to the younger generation. In addition, poetry appreciation activities can sharpen feelings, reasoning, imagination and sensitivity of the younger generation to society, culture and the environment. The realization stage of the problem is starting with teaching poetry reading material to the participants. This was done with the hope that the participants would have theoretical knowledge about poetry reading. Furthermore, an assessment or analysis of the meaning contained in the poem is carried out. this, aims so that participants can analyze and understand the meaning contained in poetry so that the poetry reading can be more appreciate. After that the poetry text critique is done in an effort to find out the advantages and disadvantages of a poetry text. Furthermore, the practice of reading poetry is done in the hope that participants can apply all theories about poetry in their reading.

Keywords: Poetry Appreciation; Sanggar Baca Jendela Dunia

\section{A. LATAR BELAKANG}

Sanggar Baca Jendela Dunia dirintis oleh sepasang suami istri yang berprofesi sebagai dosen UIN Syarif Hidayatullah, yaitu Dr. Karlina Helmanita, MA dan Dr. Sihabudin Noor, MA pada tanggal 29 Juli 2007. Pendirian ini ditandai dengan peringatan satu tahun Sanggar Baca Jendela Dunia dalam launching pustaka komunitas dan khatam al-Quran pada 10 
Agustus 2008 oleh Direktur Jenderal Perguruang Tinggi Kementrian Pendidikan Nasional, Prof. Dr. Fasli Jalal. Kemudian keberadaan sanggar dilegalkan dengan akta notaris Lilik Martono, SH pada 1 Oktober 2010. Adapun salah satu misi Sanggar Baca Jendela Dunia adalah "Menyelenggarakan pelayanan, pelatihan, pengkajian, penelitian dan penerbitan di bidang pendidikan literasi, bahasa, seni, sastra dan budaya. Namun, Sanggar Baca Jendela Dunia mengalami kesulitan dalam mencari para tutor karena lembaga ini merupakan lembaga non-profit. Sehingga, lembaga ini belum sanggup untuk memfasilitasi kesejahteraan para tutor.

Hal ini menyebabkan kurangnya minat orang untuk menjadi tutor di Sanggar Baca Jendela Dunia. Sehingga, bila tidak ada tutor maka Sanggar Baca Jendela Dunia akan kesulitan mewujudkan misinya untuk memberikan pelatihan di bidang pendidikan literasi, bahasa, seni, sastra dan budaya. Melihat permasalahan ini, maka tim abdimas berinisiatif melakukan Pelatihan Apresiasi Puisi di Sanggar Baca Jendela Dunia. Menurut Aminuddin (2010) dalam (Sukini, 2016) dijelaskan bahwa apresiasi berasal dari bahasa latin apreciatio, artinya 'mengindahkan' atau 'menghargai'. Dalam pemahaman yang lebih luas, istilah apresiasi mengandung makna: (1) pengenalan melalui perasaan atau kepekaan batin, (2) pemahaman dan pengakuan terhadap nilai-nilai keindahan yang diungkapkan pengarang (Ismawati, 2017). Secara sederhana apresiasi dapat diartikan sebagai kemampuan memahami/menilai sesuatu.

Sedangkan menurut Kamus Besar Bahasa Indonesia (2008) apresiasi adalah (1) kesadaran terhadap nilai seni dan budaya; (2) penilaian (penghargaan) terhadap sesuatu; (3) kenaikan nilai barang karena harga pasarnya naik atau permintaan akan barang itu bertambah. Jadi, mengapresiasi puisi berarti kesanggupan dalam mengenal, memahami, menghargai, menilai dan member makna terhadap puisi yang dibaca (Marantika, 2014), (Ismawati, 2017), (Noor, 2018).

Menurut Indriati dan Haryadi (2014) kompetensi dasar yang ingin dicapai dalam pembelajaran puisi meliputi beberapa aspek keterampilan, membaca, menulis, menyimak, dan berbicara, namun pada praktiknya sebagian besar pembelajaran puisi baru sampai pada aspek membaca (Indriati \& Haryadi, 2014). Pembelajaran puisi di sekolah cenderung mengajarkan pengetahuan tentang teori puisi bukan keterampilan berpuisi (Gumbira, 2014).

Kondisi pengajaran sastra yang semacam itu tidak saja memprihatinkan, tetapi juga telah "membusukkan" proses pencerdasan emosional dan spiritual siswa. Apalagi dalam apresiaisi puisi dalam hal pemberian makna atau konkretisasi puisi belum tergarap dengan maksimal (Aziz, 2012). Oleh sebab itu, kegiatan peningkatan kemampuan apresiasi puisi bagi siswa di Sanggar Baca Jendela dunia secara umum bertujuan untuk membina kemampuan apresiasi pembelajar terhadap puisi. Dalam berapresiasi puisi, pelajar diajak mengenal, memahami, menggauli puisi secara sungguh-sungguh sehingga timbul pengertian, penghargaan, kepekaan pikiran kritis dan kepekaan perasaan-baik terhadap puisi.

Puisi sebagai objek apresiasi merupakan susunan yang sangat majemuk yang mempunyai karakter yang berlapis-lapis sehingga dalam pembelajaran apresiasi puisi pembelajar harus diajak mengenal, 
memahami, menghargai persajakannya, iramanya, citraannya, gaya bahasanya, tema, amanat, nada, rasa, dan lain-lain yang termasuk ke dalam anatomi puisi (Indriyana Uli, Muhammad Zikri Wiguna, 2016). Kegiatan Pelatihan Apresiasi Puisi di Sanggar Baca Jendela Dunia dimulai dengan pengajaran dan pengayaan materi penulisan.

Selanjutnya, dilakukan pengkajian atau analisis makna (pesan) yang terkandung dalam puisi. Setelah itu, dilakukan praktek pembacaan puisi. Kegiatan ini bertujuan untuk membantu Sanggar Baca Jendela Dunia dalam mewujudkan misinya, yaitu memberikan pelatihan di bidang bahasa dan sastra. Selain mewujudkan salah satu misi Sanggar Baca Jendela Dunia. Kegiatan ini juga bertujuan untuk memperingati Bulan Bahasa. Dengan harapan, dapat membina, mengembangkan dan mewariskan Sastra Indonesia kepada generasi muda. Selain itu, menurut Prayitno (2013), kegiatan apresiasi puisi dapat mempertajam perasaan, penalaran, daya khayal serta kepekaan generasi muda terhadap masyrakat, budaya dan lingkungan hidup (Prayitno, 2013).

\section{B. METODE PELAKSANAAN}

Kegiatan pengabdian masyarakat dilakukan di Komunitas Sanggar Baca Jendela Dunia. Tempat yang memfasilitasi peningkatan minat baca dan peningkatan pengetahuan sosial, budaya, agama, sastra dan seni anak-anak di lingkungan Sanggar, yaitu di RT 01 RW 02, Legoso, Ciputat Timur, Tangerang Selatan.

Tim pengabdian masyarakat terdiri dari 4 orang dosen dan 7 mahasiswa Program Studi Sastra Indonesia Universitas Pamulang. Jumlah peserta peningkatan kemampuan apresiasi puisi sebanyak 30 orang. Kegiatan ini dilakukan selama 3 kali pertemuan dalam 3 minggu, yaitu tanggal 19 September 2019 pertemuan pertama, 26 September 2019 pertemuan kedua dan 3 Oktober 2019 pertemuan ketiga.

Berikut dipaparkan mengenai langkah-langkah pelaksanaan kegiatan peningkatan kemampuan apresiasi puisi di Sanggar Baca Jendela Dunia.

\section{Persiapan dan Pembekalan}

a. Mekanisme pelaksanaan kegiatan peningkatan kemampuan apresiasi puisi di Sanggar Baca Jendela Dunia meliputi tahapantahapan berikut; a) penentuan anggota dosen dan mahasiswa, b) konsultasi dengan Sanggar Baca Jendela Dunia, c) pembekalan (coaching) bagi mahasiswa, d). penyiapan sarana dan prasarana terkait dengan pelaksanaan kegiatan

b. Materi persiapan dan pembekalan kepada mahasiswa mencakup: Sesi Pembekalan/Coaching dan pembagian tugas mahasiswa dalam kegiatan peningkatan kemampuan apresiasi puisi di Sanggar Baca Jendela Dunia

c. Membuat panduan dan pelaksanaan program peningkatan kemampuan apresiasi puisi di Sanggar Baca Jendela Dunia

d. Perancangan model kegiatan peningkatan kemampuan apresiasi puisi di Sanggar Baca Jendela Dunia. 


\section{Pelaksanaan Kegiatan}

Kegiatan apresiasi puisi di Sanggar Baca Jendela Dunia berlangsung dari tanggal 19 September- 3 Oktober 2019.

a. Persiapan acara oleh dosen dan mahasiswa

b. Berangkat menuju lokasi apresiasi puisi di Sanggar Baca Jendela Dunia

c. Sambutan dari Ketua Pengabdian Masyarakat dan Ketua Sanggar Baca Jendela Dunia

d. Pengarahan lapangan oleh dosen kepada mahasiswa

e. Pelaksanaan bentuk program yang akan dilaksanakan oleh dosen dan mahasiswa kepada peserta adalah pengajaran dan pengayaan materi penulisan puisi, pengkajian atau analisis makna yang terkandung dalam puisi dan praktek pembacaan puisi.

\section{Pasca Kegiatan}

a. Monitoring dan evaluasi per minggu kegiatan apresiasi puisi di Sanggar Baca Jendela Dunia

b. Monitoring dan evaluasi pertengahan kegiatan apresiasi puisi di Sanggar Baca Jendela Dunia

c. Monitoring dan evaluasi akhir kegiatan apresiasi puisi di Sanggar Baca Jendela Dunia

d. Rencana Keberlanjutan Program Proses pelaksanaan keberlanjutan program ini yakni dosen dan mahasiswa akan melakukan pendampingan yang intensif dan terarah dalam literasi sastra Sanggar Baca Jendela Dunia. Selain itu, menempatkan mahasiswa pada berbagai program Sanggar Baca Jendela dalam rangka mewujudkan misi Sanggar Baca Dunia dalam rangka menyelenggarakan pelayanan, pelatihan, pengkajian, dan penelitian, dan penerbitan di bidang pendidikan literasi, bahasa, seni, sastra, dan budaya.

\section{HASIL DAN PEMBAHASAN}

Tempat pengabdian masyarakat berada di Komunitas Sanggar Baca Jendela Dunia, Jalan Legoso Raya No. 69, RT01/RW02, Pisangan, Ciputat Timur, Tangerang Selatan. Salah satu kendala yang dihadapi oleh Sanggar Baca Jendela Dunia adalah pemberian pelatihan apresiasi puisi kepada anggota Sanggar Baca Jendela Dunia. Hal ini dapat dilihat dari bukti berikut, pengurus Sanggar Baca Jendela Dunia belum pernah memberikan pelatihan apresiasi puisi kepada anggotanya. Hal ini dapat menghambat Sanggar Baca Jendela Dunia dalam mewujudkan misinya dalam menyelenggarakan pelayanan, pelatihan, pengkajian, penelitian dan penerbitan di bidang pendidikan literasi, bahasa, seni, sastra dan budaya. Oleh sebab itu, tim dosen Program Studi Sastra Indonesia mencoba untuk menyelesaikan atau memberikan solusi dari permasalahan yang dihadapi oleh Sanggar Baca Jendela Dunia. Dengan cara memberikan pelatihan apresiasi puisi di Sanggar Baca Jendela Dunia. 
Adapun tahap realisasi permasalahannya adalah dimulai dengan pembekalan pengetahuan tentang puisi kepada para peserta. Selanjutnya, dilakukan praktek penulisan puisi masing-masing peserta. Hal ini, bertujuan agar peserta mampu mencurahkan perasaan dan pengamatannya dalam kehidupan menjadi sebuah puisi. Selanjutnya, dilakukan praktek pembacaan puisi dengan harapan agar peserta dapat menghayati isi yang terkandung dalam puisi. Uraian kegiatan yang telah dilakukan dijabarkan sebagai berikut.

\section{Pembekalan Pengetahuan Tentang Puisi}

Kegiatan ini dilakukan dengan harapan agar para peserta memiliki pengetahuan tentang puisi. Materi yang disampaikan pada kegiatan ini adalah pengertian puisi, struktur puisi, penulisan puisi menggunakan pendekatan panca indra dan materi pembacaan puisi agar dalam pembacaan peserta bisa menghayati isi yang terkandung dalam puisi. Pada kegiatan ini, penulisan puisi masih bersifat kolektif, peserta diintruksikan menggunakan pengamatan panca indra untuk menentukan sebuah diksi untuk dirangkai menjadi sebuah puisi. Gambar 1 dan Gambar 2 adalah dokumentasi kegiatan pembekalan pengetahuan tentang puisi.
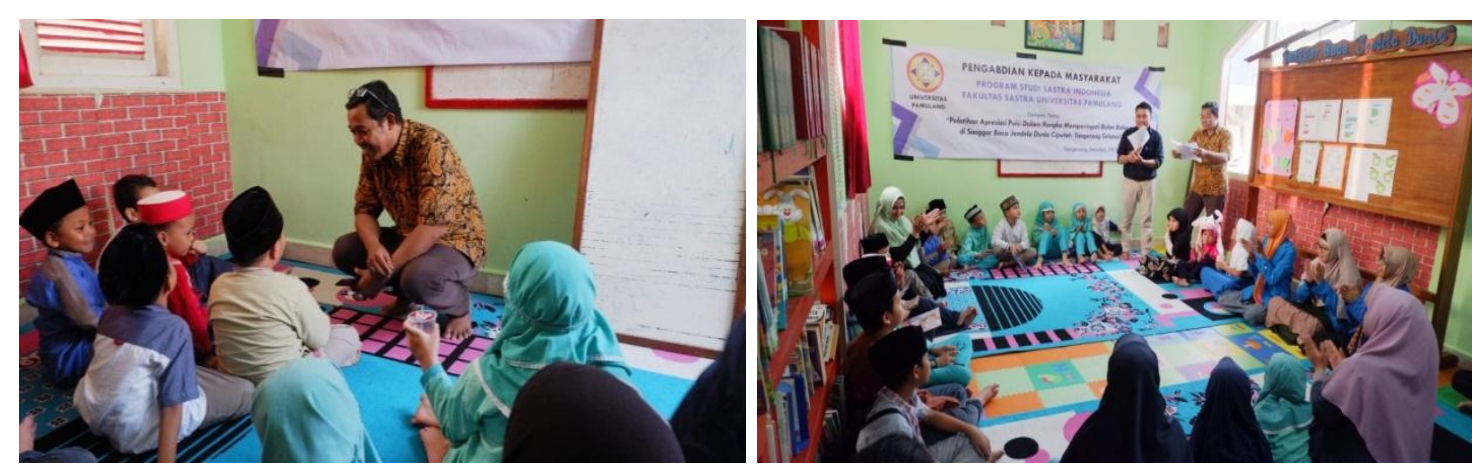

Gambar 1. Pembekalan Pengetahuan Tentang Puisi

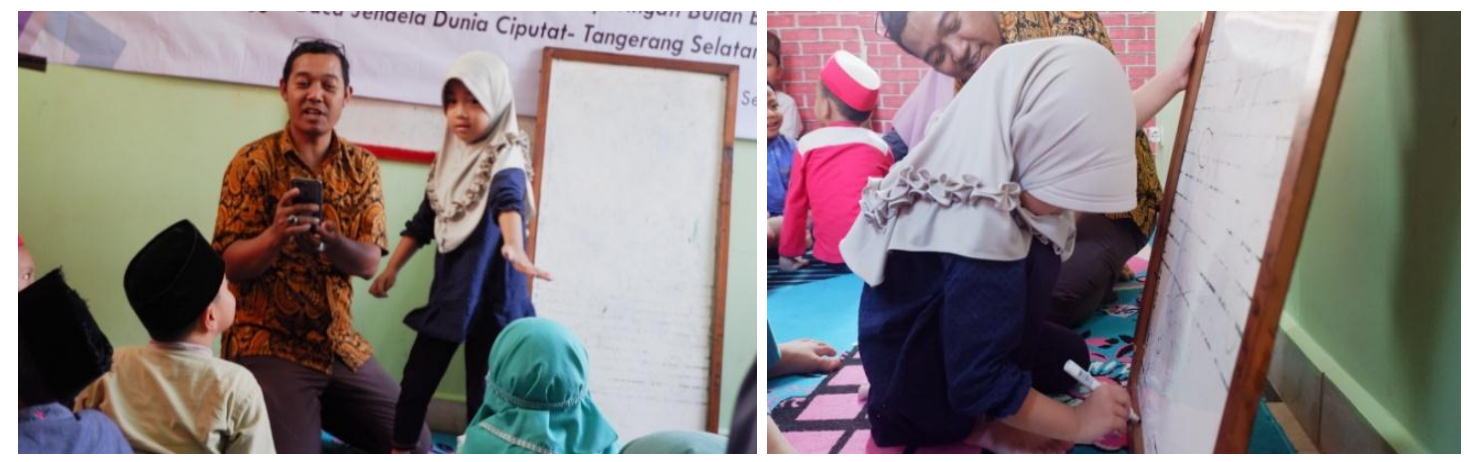

Gambar 2. Pembekalan Penulisan dan Pembacaan Puisi

\section{Penulisan Puisi}

Pada tahap ini dilakukan praktek penulisan puisi dengan harapan agar para peserta mampu membuat puisi. Kegiatan ini dilaksanakan di ruangan Sanggar Baca Jendela Dunia. Penulisan puisi dilakukan oleh masing-masing individu peserta dan dipandu oleh mahasiswa dan dosen. Selain itu, peserta juga dibagi menjadi beberapa kelompok dalam membuat puisi. Kelompok tersebut disuruh untuk menyusun potongan-potongan diksi (puzzle) sehingga menjadi sebuah puisi. Gambar 3 dan Gambar 4 adalah dokumentasi kegiatan penulisan puisi. 

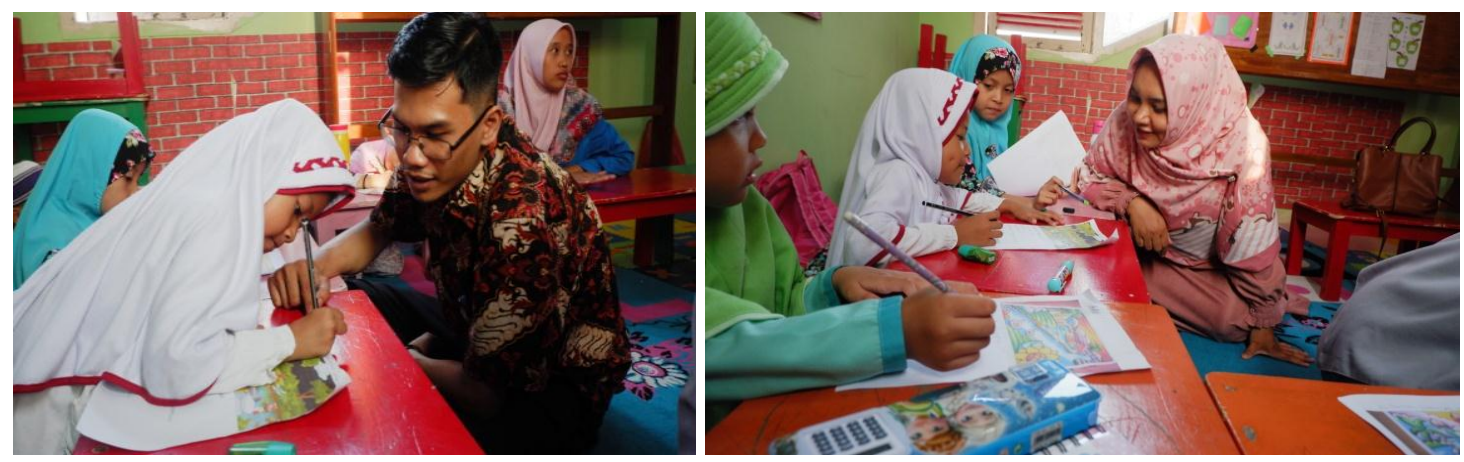

Gambar 3. Penulisan Puisi Masing-masing Peserta
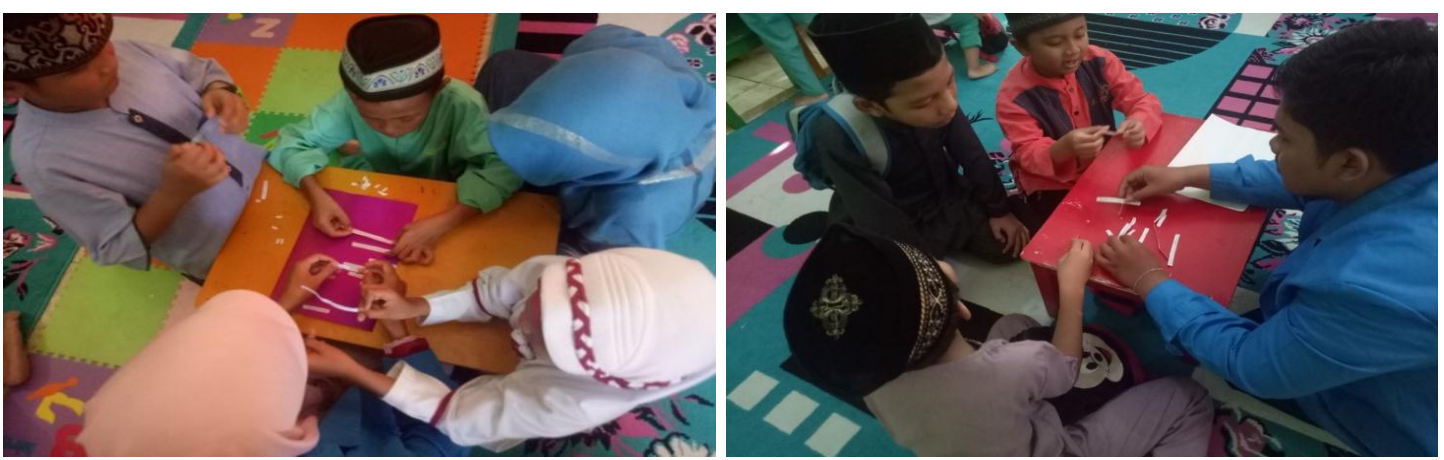

Gambar 4. Penulisan puisi Berkelompok Menyelesaikan Puzzle

\section{Pembacaan Puisi}

Setelah dilakukan penulisan puisi, dilakukan pembacaan puisi yang sudah ditulis. Sebelum peserta membaca puisi, dosen dan mahasiswa memberikan contoh membaca puisi dengan penghayatan. Selanjutnya, peserta disuruh membacakan puisinya masing-masing. Gambar 5 dokumentasi kegiatan pembacaan puisi.
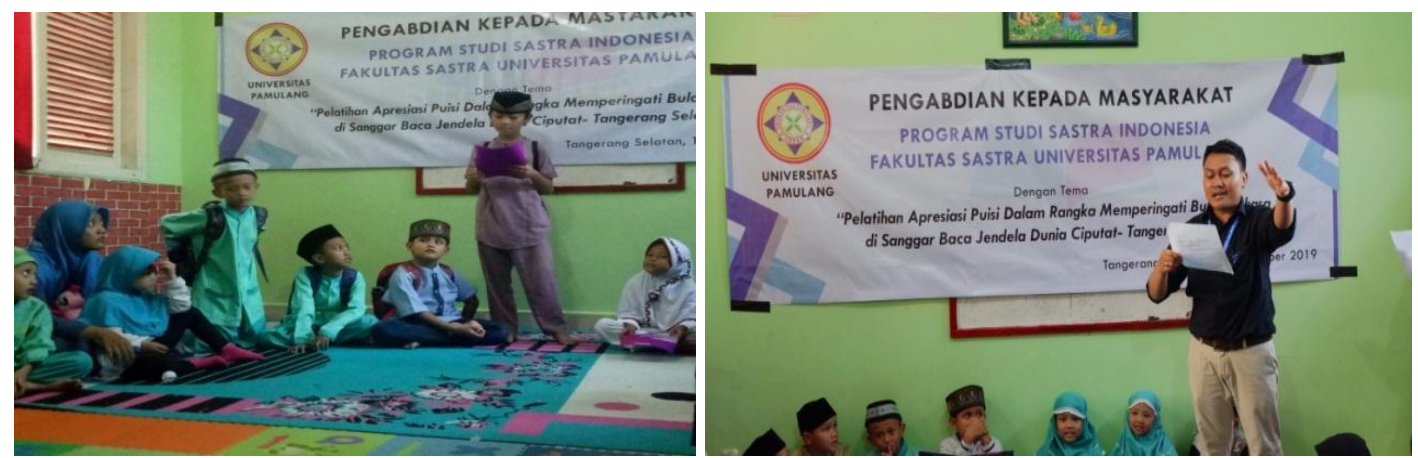

Gambar 5. Pembacaan Puisi oleh Tim Abdimas dan Peserta

\section{SIMPULAN DAN SARAN}

Kesimpulan kegiatan pelatihan apresiasi puisi di Sanggar Baca Jendela Dunia mendapat respon yang sangat baik dari pimpinan yayasan, mentor dan peserta pelatihan. Kegiatan pengabdian masyarakat ini bertujuan untuk mewujudkan salah satu misi Sanggar Baca Jendela Dunia dalam memberikan pelatihan di bidang sastra. selain itu juga bertujuan menyambut bulan bahasa sehingga generasi muda mengenali dan mencintai sastra Indonesia.

Adapun hasil dari kegiatan ini menyimpulkan beberapa indikator. Pertama, seluruh peserta memiliki antusias yang tinggi dalam mengenali 
dan mempelajari puisi. Kedua, hanya sebagian peserta yang mampu menulis puisi secara baik, yaitu peserta yang berusia 6-8 tahun. Jumlah peserta yang berusia 6-8 tahun sebanyak 15 orang. Jadi, kalau dipersentasekan $15 \div 30 \times 100 \% \equiv 50 \%$. Ketiga, dalam pembacaan puisi peserta belum mampu menghayati isi yang terkandung dalam puisi yang dibacanya.

Saran bagi tim selanjutnya yang ingin memberikan pelatihan puisi di Sanggar Baca Jendela Dunia. Pertama, tim pengabdian masyarakat dalam memberikan pelatihan harus mengelompokkan peserta berdasarkan usianya. Kedua, berhubung peserta masih dalam usia dini metode pengajaran puisi harus disesuaikan dengan usianya sehingga dapat merangsang anak-anak untuk belajar mengenal dan memahami puisi.

\section{UCAPAN TERIMA KASIH}

Ucapan terima kasih kami sampaikan kepada Rektor dan ketua LPPM Universitas Pamulang yang telah mendanai kegiatan ini. Selanjutnya, ketua Yayasan Sanggar Baca Jendela Dunia yang telah mengizinkan tim dosen Sastra Indonesia Universitas Pamulang memberikan pelatihan apresiasi puisi di tempatnya. Selanjutnya, mentor Sanggar Baca Jendela Dunia yang telah membantu dalam pelatihan ini sehingga kegiatan ini dapat berjalan dengan baik dan lancar. Kemudian, tim dosen dan mahasiswa yang telah memberikan pemahaman tentang puisi kepada peserta. Selanjutnya, ucapan terima kasih kepada semua pihak yang telah membantu kegiatan ini.

\section{DAFTAR RUJUKAN}

Aziz Amin, M. (2012). Keefektifan Pembelajaran Apresiasi Puisi Dengan Analisis Struktural dan Analisis Semiotik Berdasarkan Gaya Berfikir Sekuensial-Acak Pada Siswa SMP. Seloka: Jurnal Pendidikan Bahasa Dan Sastra Indonesia, 1(2), 129-135.

Gumbira, G. (2014). Pembelajaran Mengapresiasi Puisi Pada Siswa Kelas Viii G Smp Negeri 2 Lembang Dengan Menggunakan Teknik Jigsaw. Bahtera Bahasa: Antologi Pendidikan Bahasa Dan Sastra Indonesia, 1(5).

Indriati, D. A., \& Haryadi, H. (2014). Peningkatan Apresiasi Puisi Dalam Pembelajaran Puisi Dengan Media Musik Di SMA Negeri 11 Yogyakarta. LingTera, 1(2), 156. https://doi.org/10.21831/lt.v1i2.2593

Indriyana Uli, Muhammad Zikri Wiguna, R. A. (2016). Analisis Gaya Bahasa Pada Lirik Lagu Daerah Pontianak Dan Pemanfaatannya Sebagai Bahan Pembelajaran Apresiasi Puisi Di Sma. Jurnal Pendidikan Bahasa, 5(1), 100115.

Ismawati, E. (2017). Mantra Bumi Karya Aprinus Salam sebagai Bahan Ajar Apresiasi Sastra. Makalah PIBSI Undip.

Marantika, J. E. R. (2014). Drama Dalam Pembelajaran Bahasa dan Sastra. Tahuri, 11(2), 92-102.

Noor, A. Z. (2018). Apresiasi Puisi Dalam Gerakan Literasi. Jurnal Pendidikan Bahasa Dan Sastra Indonesia, 13(2). https://doi.org/10.25134/fjpbsi.v13i2.1540

Prayitno, H. W. (2013). Peningkatan Keterampilan Menulis Puisi Menggunakan Teknik Inkuiri dan Latihan Terbimbing. Jurnal Pendidikan Bahasa Dan Sastra Indonesia Universitas Negeri Semarang, 2(1), 1-10.

Sukini. (2016). Apresiasi Puisi Apa dan Bagaimana Pembelajarannya di Perguruan Tinggi. Magistra, 42-55. 